\title{
El riesgo de judicialización de la medicina
}

\author{
Ana Victoria Revuelta Iglesias
}

Servicio de Formación Continua del Consejo General del Poder Judicial.

\section{INTRODUCCIÓN}

El riesgo de judicialización de la medicina es inmanente al desempeño de cualquier actividad que se realice en el ejercicio de las profesiones sanitarias. Así cualquier médico se encuentra permanentemente expuesto a la realización de actos susceptibles de calificar por su resultado dañoso, de culposos y que por ello den lugar a una reclamación ante los tribunales.

El art. 43 de la Constitución Española reconoce como derecho fundamental la protección de la salud y no hay duda de que en la sociedad en los últimos 25 años se ha producido el reconocimiento genérico de un abanico de derechos cada vez mas amplio y que la conciencia ciudadana de los derechos que la Constitución y las leyes nos conceden a todos, ha provocado que en los últimos años las reclamaciones contra los médicos y la sanidad hayan aumentado considerablemente tanto en número como en importe de la reclamación.

Si reflexionamos sobre dicho aumento nos damos cuenta de que si los medios con los que cuenta la sanidad tanto pública como privada, son cada vez mayores y de mas calidad y la formación que reciben los profesionales es cada vez mas depurada y la formación, cada vez mas perfecta y continuada, y eso a su vez coincide con un incremento en el número de las reclamaciones, dicho aumento no puede deberse mas que a la voluntad de los ciudadanos en plantear dichas reclamaciones que generalmente terminan en los tribunales de Justicia a los que la Constitución ( en su art. 17) encomienda la obligación de ejercer la potestad jurisdiccional en todo tipo de procesos. No se olvide que el art. 10.12 de la ley General de Sanidad, entre los derechos de los ciuda- danos en relación con la administración pública sanitaria reconoce el derecho " a utilizar las vías de reclamación".

Es la propia sociedad la que demanda de los médicos una actuación mas exquisita y ello se refleja en un aumento de las reclamaciones lo que obliga a poner a los Jueces y tribunales en marcha mecanismos previstos por algunas leyes procesales (criminales, civiles o contenciosos) y a pronunciarse sobre la corrección y la adecuación de la actividad profesional de los médicos.

Si a lo anterior unimos la promulgación de la Ley 41/2002 Reguladora de la autonomía del paciente y derechos y obligaciones en materia de información y documentación clínica, que institucionaliza y consagra un estatuto del paciente de forma definitiva y bien diferente a la situación que hasta época relativamente reciente teníamos, concluimos que la judicialización de la medicina es una realidad tangible en nuestra sociedad, y que desde este punto de vista la condición d enfermo de una persona no la relega a una suerte de incapacidad frente al poder del medico. Si durante siglos la actividad del profesional sanitario, del que el médico es arquetipo, se rigió por el denominado principio de beneficencia, en el que el médico se consideraba legitimado para actuar de acuerdo con la voluntad del enfermo, pero también sin su voluntad o incluso contra ella, el mismo fue evolucionando a la afirmación de la autonomía del paciente, con un poder de autodeterminación que debe ser respetado por el médico, quien no puede imponer tratamientos coactivos por bienintencionados que sean, de ahí que uno de los principales derechos del enfermo sea el del consentimiento informado o derecho de información. 


\section{EFECTOS QUE PRODUCE LA JUDICIALIZACIÓN DE LA MEDICINA: LA PRÁCTICA DE LA MEDICINA DEFENSIVA}

La extraordinaria proliferación en el número de reclamaciones dirigidas contra los médicos provoca que por parte de estos se practique de forma inexorable lo que se ha venido a llamar medicina defensiva. Será difícil establecer un criterio que satisfaga a todos sobre lo que se entiende por medicina defensiva, pero, sin perjuicio de lo que podamos concluir al amparo del Código de Deontología , quizá podamos admitir que cuando hablamos de medicina defensiva, estamos hablando de que los médicos para evitar que se les impute mala práctica, prescriben la realización de pruebas diagnosticas que exceden con mucho de las que serían habituales y ordenan la práctica de todo el abanico de pruebas que la medicina moderna les permite para evitar tanto un diagnostico equivocado, como que les puedan tachar de dejadez o abandono en la investigación de la causa de la enfermedad.

La medicina defensiva trataría de proporciona al médico la protección necesaria ante futuras reclamaciones planteadas por los posibles perjudicados por la prestación asistencial recibida, de modo que el medico ante el que se formule la reclamación, estuviera en condiciones de probar en todo caso que se actuó con arreglo a los protocolos aplicables y que la prestación asistencial fue conforme al criterio de la lex artis, entendida esta como criterio de normalidad en la prestación asistencial. La actuación médica "a la defensiva" supone que se practiquen las pruebas diagnosticadas y que se actúe tomando no solo las precauciones normales (en las que siempre se corre algún riesgo, pues no puede garantizarse que siempre la salud y la vida triunfen en le combate contra la enfermedad) sino mas allá de las normales, acentuando hasta el límite máximo las precauciones con el fin de reducir al mínimo de lo razonable los riesgos derivados del tratamiento medico.

La práctica de la medicina defensiva, considerada tal como hemos hecho en los párrafos anteriores lleva aparejada dos consecuencias fundamentales igualmente perniciosas para el sistema sanitario: por un lado ocasiona una ralentización en la prestación asistencial, y por otro provoca que se encarezca la asistencia prestada por cuanto supone la realización de pruebas de las que se habría podido prescindir. Se infringe frontalmente de este modo lo previsto en el art.7 de la Ley General de Sanidad que esta- blece que: "Los servicios sanitarios...adecuaran su organización y funcionamiento a los principios de eficacia, celeridad, economía y flexibilidad", y ello pues dicha actitud estaría infringiendo, al menos, los principios de celeridad y economía.

Pero la práctica de la medicina defensiva tiene inconvenientes que superan con mucho lo que es la simple demora en la prestación asistencial ó el encarecimiento en el coste económico de la misma. Lo que es preocupante es que los médicos en su actuar no tengan fijado su norte sólo en la curación del enfermo ( que es el primer y primordial deber del médico según establece el art. 4 del Código de Deontología redactado por la Organización médica colegial ) y en adoptar las medidas y tratamientos mas acomodados a este fin, sino que al practicar medicina defensiva los médicos actúan del modo que consideran mas adecuado para evitar las reclamaciones de los pacientes, lo que supone actuar sometidos a una presión añadida a la habitual de su trabajo y que debe producir efectos perniciosos en el propio médico y en la asistencia sanitaria que presta.

No se olvide que en el segundo párrafo del art. 18 de Código Deontológico al que hacíamos referencia antes, se establece que "el médico no debe indicar exploraciones ó tratamientos que no tengan otro fin que la curación del enfermo. La medicina defensiva es contraria a la medicina ética". En principio dicho precepto es claro y sirve no solo como reflejo de que el ejercicio de la medicina defensiva está prohibida por la Organización Médica colegial, sino que también nos permite obtener un concepto de lo que debe entenderse por medicina defensiva: "Puede entenderse que es aquella en que se prescriben exploraciones, ó tratamientos que no tienen finalidad terapéutica sino que buscan la protección del médico ante eventuales reclamaciones"

En cualquier caso la medicina defensiva no es fácilmente evitable en la práctica y ello desde que el art. 20 del mismo Código Deontológico atribuye al médico la libertad de prescripción como garantía de su actuar con independencia y con garantía de calidad.

Como consecuencia de la práctica de esta medicina defensiva se produce una alteración de los parámetros con los que se debe valorar la corrección de la prestación asistencial médica, la Lex artis, que es un criterio esencial para determinar la existencia o no de responsabilidad, entendida dicha lex artis como criterio de normalidad en la prestación asistencial sanitaria. Y así los criterios de normalidad se alteran para ser sustituidos por otros donde la 
normalidad ya no es lo habitual sino que se convierten en criterios más exigentes, con la única finalidad de evitar reclamaciones por parte de los pacientes.

Es cierto que el avance de la ciencia médica y la proliferación de nuevos y mas perfectos métodos diagnósticos obliga a que el criterio de normalidad de la lex artis sea cambiante con los tiempos, los protocolos asistenciales debe ir mejorado impulsados por el avance de la ciencia, pero lo que no es admisible es que la modificación de la lex artis la marque no el avance de la ciencia, sino el carácter cada vez mas defensivo de la práctica de la medicina, que lleva a considerar normales cosas que no lo son.

Todo esto tiene efectos directos en los procedimientos que se tramitan en relación a las reclamaciones: así cuando se interroga a un perito judicial sobre si la práctica médica de ha realizado conforme a la lex artis o no, las respuestas son cada vez menos contundentes y así lo que se consideraba un tratamiento acorde a la normalidad, ahora se considera notablemente insuficiente pues se complementa con toda clase de pruebas terapéuticas y diagnosticas que si bien no resultan del todo innecesarias sirven para asegurar que nunca pueda prosperar una reclamación por asistencia inadecuada o defectuosa, de tal modo que para el caso de que se produzca un resultado dañoso se pueda acreditar que siempre es imputable a la evolución natural de la enfermedad y no a la deficiente asistencia prestada.

Se concluye que la mayor exigencia de los ciudadanos en relación a la prestación sanitaria y el aumento de las reclamaciones y de las denuncias, ocasiona las modificaciones de los niveles de normalidad asistencial, lo que tiene efectos directos en la fijación de parámetros de la lex artis.

\section{RESPONSABILIDAD DEL MÉDICO EN SU RELACIÓN CON EL PACIENTE}

La actividad médica ha ido incrementándose en la época actual como hemos expuesto antes y, por consiguiente la exigencia de responsabilidad a los profesionales de la medicina, cuya actividad puede y debe ser sometida al juicio crítico de los Tribunales de Justicia cuando se haya producida cualquier tipo de incumplimiento lesionador de la salud de los pacientes. La sociedad, manifestándose a través de la opinión pública, esta siendo muy sensible a esta problemática y el Derecho se interesa cada vez mas en la Medicina, y particularmente en las consecuencias jurídicas que se derivan del ejercicio profe- sional, una vez que es transgredido el ordenamiento jurídico.

El afectado por un resultado dañoso en el ámbito de la medicina puede ejercitar sus acciones tanto penales como civiles frente:

a) al profesional médico o sanitario

b) al Centro sanitario donde se produjo el acto médico.

c) a la entidad aseguradora ya sea pública o privada.

La responsabilidad del médico, entendiéndola tanto desde el punto de vista penal, imprudencia), como civil (negligencia), tiene como objetivo principal la reparación económica de un daño derivado de su actividad profesional, y su diferencia se encuentra en una frontera poco clara y muy difuminada entre la culpa civil y la imprudencia leve, esta última conlleva un plus de antijuricidad que implica un reproche social mas grave y que exige una sanción penal. La intensidad de sus elementos definidores son: A) una acción culposa o negligente, o imprudente determinada por una mala praxis médica. B) El daño. C) La relación de causalidad.

Los sujetos mas directamente implicados en este marco de la responsabilidad sanitaria, el médico y el paciente, están unidos por una relación jurídica contractual o extracontractual que genera en el peor de los casos, cuando se produce daño alguno, la obligación de repararlo, bien por el incumplimiento de las obligaciones, o por imputarse el médico una acción culposa o negligente (art. 1101 y 1902 CC) acción que en determinados supuestos puede ser calificada de delito/ falta imprudente y que igualmente genera la obligación de resarcimiento por el daño causado (arts. 142, 147, 149, 150, y 621.1del CP.) El Centro Hospitalario es también responsable de un resultado dañoso en un paciente, bien en el ámbito de la sanidad pública como servicio público que es y su responsabilidad patrimonial en consecuencia, bien en el marco del centro privado en virtud del acto médico realizado por el profesional dependiente del mismo, o por la relación jurídica con el centro en el denominado contrato hospitalario.

La relación del médico y su paciente deviene en virtud de un contrato o negocio jurídico entre ambos del que nacen una serie de derechos y obligaciones recíprocos cuyo exponente obligacional es el art.1091del CC. Siguiendo con el mismo cuerpo legislativo el art 1544 ofrece una regulación en base al llamado contrato de arrendamiento de servicios o 
de obra, en el primero la obligación fundamental es la prestación asistencial a un paciente pero no su curación, el médico se obliga a desplegar con el paciente su eficacia y sus conocimientos en cuanto a la especialidad que desarrolla y tiene el deber de seguir el tratamiento. Respecto del segundo, el contrato de obra, el médico está obligado a la consecución de un resultado, estableciéndose entonces una distinción importante a la hora de calificar la Medicina, así en el primer supuesto la medicina que se despliega es la medicina curativa terapéutica o asistencial, y en el segundo supuesto nos encontramos ante la medicina satisfactiva, en sus dos facetas de estética o preventiva.

La responsabilidad médica curativa mantiene la obligación de prestar el tratamiento mas adecuado al enfermo en orden a la consecución de un resultado, la salud del enfermo, pero la obligación en si no es la consecución de un resultado. A diferencia de ésta, la medicina satisfactiva se despliega para obtener un resultado, este es su obligación, se ejecuta la prestación bajo su propio riesgo, ya que solo hay cumplimiento si se produce el resultado. En la obligación de actividad, la realización de una conducta diligente basta para que se considere cumplida.

\section{1.- Requisitos y elementos comunes de la res- ponsabilidad civil y penal del médico en su actuación profesional.}

La responsabilidad del médico tiene su punto de partida en el propio acto médico y se enmarca en el concepto clásico de culpa, entendiendo esta como la omisión de la diligencia o del deber de cuidado normalmente exigido por el ordenamiento jurídico, por las costumbres o las reglas de convivencia social, referida en el ámbito de la conducta de los profesionales de la medicina, a la observancia de esa diligencia desde un sentido estrictamente técnico, ya que su actividad esta regulada por las reglas del arte de su profesión, que es lo que se denomina lex artis. El médico compromete su responsabilidad si ignora o se aparta de las reglas del arte ya que promete ejercer su profesión con la pericia que su requiere, y responde de su ignorancia, pues la impericia se cuenta como culpa. Para ejercer diligentemente la actividad médica y con arreglo a las leyes del arte es necesario que el facultativo cuente con conocimientos técnicos correspondientes, obligación que descansa en la propia naturaleza de su profesión y que se recoge en el art.29 del Código de Deontología Profesional médica.

Sin embargo, la lex a rtis siempre ha de estar referida al caso concreto, es lo que se llama lex artis ad hoc, por la variedad de situaciones que se pueden presentar en la actuación típica prevista por la ciencia médica. Las exigencias de la lex artis siempre son las mismas, pero su contenido es variable según las diversas circunstancias en que se encuentre el facultativo.

Y así refiriéndonos a la específica imprudencia punible, (por cuanto las denuncias o querellas son las mas habituales formas de plantear una reaclamación por daños ocasionados en al ámbito sanitario) cometida en el desempeño de las profesiones sanitarias, y siguiendo la sentencia del TS, de la Sala II de 13-3-1990, son hasta cinco los elementos que caracterizan la imprudencia:

$1^{\circ}$ La no incriminación, vía delito, del delito de imprudencia en función de un simple error científico o del diagnóstico equivocado, salvo cuando por su propia categoría o entidad cualitativa o cuantitativa resulten de extrema gravedad.

$2^{\circ}$ Tampoco se reputa como elemento constitutivo sin mas de la imprudencia el hecho de carece el facultativo de una pericia que pueda considerarse extraordinaria o de cualificada especialización.

$3^{\circ}$ No es posible hacer en este campo una formulación de generalizaciones aplicables a todos los supuestos, sino que es indispensable, acaso con mayor razón que en otros sectores, la individualizada reflexión sobre el supuesto concreto de que se trate.

$4^{\circ}$ Mas allá de puntuales deficiencias técnicas o científicas, ha de ponerse el acento de la imprudencia en el comportamiento específico del profesional que pudiendo evitar con una diligencia exigible a un médico normal el resultado lesivo o mortal para una persona, no pone a su contribución una actuación impulsada a contrarrestar las patologías existentes con mayor o menor acierto;

$5^{\circ}$ Si las deficiencias del material o instrumental técnico no son imputables o no consta que lo fueran a los facultativos, no existe tampoco la imprudencia."

De estos requisitos que exige la jurisprudencia merece la pena destacar dos: el alcance de la lex artis, a la que nos hemos referido antes y las reglas de la imputación objetiva, encargadas de dar solución a los problemas de la causalidad que se producen en la práctica. 


\section{A. Respecto a la lex artis:}

"Se erige en elemento indispensable para la comprobación de la adecuación de la actividad profesional a la norma de cuidado que se dice inobservada, configurando "las reglas de actuación" de las ciencias médicas" (SAP Tarragona 11-12-2000)

"Es un modelo de cumplimiento ordinario o regular del oficio médico" (STS 5-5-1989)

"El profesional que se aparta de estas normas específicas que le obligan a un especial cuidado, merece un mayor reproche en forma de sanción punitiva" ( STS 3-10-1997)

"Se produce la quiebra de la lex artis cuando en el tratamiento efectuado el paciente se incida en conductas desviadas de las que resulte un proceder irreflexivo, la falta de adopción de cautelas de generalizado uso o la ausencia de pruebas, investigaciones o verificaciones precisas como imprescindibles para seguir el curso del estado del paciente."(SAP Las Palmas 5-7-2000)

"La lex artis ad hoc es el criterio valorativo de la corrección del acto médico específico ejecutado por el profesional de la medicina que tiene en cuenta las especiales características de su autor, de la profesión, de la complejidad y trascendencia vital del acto y en su caso de la influencia de otros factores exógenos (estado del paciente, de sus familiares o de la propia organización sanitaria)."(SAP de Salamanca 23-2-2001)

Sea como fuere, la infracción de la norma de cuidado que apareja el abandono de la lex artis habrá de ser valorada judicialmente a la vista de los correspondientes informes periciales, el Juez o Tribunal se apoyará en estos, para realizando una labor de cotejo entre la concreta praxis que origina el procedimiento y la que hipotéticamente debería haberse realizado atendidos los postulados que conforman la lex artis, concluir que la actuación del médico lo fue conforme a ella. El ejercicio de ponderación es jurisdiccional y no deberá ser simplificado por el recurso al valor omnímodo de las periciales.

\section{B. Causalidad:}

La gran variedad de actuaciones médicas que pueden concurrir en las fases de amnesis o recogida de datos previos, diagnosis y fase terapéutica ( STS 912-1993) hace que en la recreación judicial de los actos presuntamente delictivos se deba señalar con suficiente exactitud cual o cuales de ellos son los que verdaderamente han resultado ser idóneos para la producción del resultado lesivo. Además también es muy frecuente que en estos procesos intervengan varios profesionales, por lo que será necesario conocer a quién debe realmente imputarse el resultado.

Como punto de partida, es necesario recordar que la causalidad es un nexo que ha de concurrir entre la acción y el resultado para que este pueda imputarse al autor como hecho propio y exige que la acción se halle entre las condiciones del resultado con sujeción a criterios derivados de las leyes naturales o de la experiencia, pero necesita además una relación específica que permita imputarle objetivamente el resultado.(STSS4-11-1992 Y 30-4-1997). Los delitos imprudentes precisan un tratamiento especial en la cuestión de la causalidad, pues en esta clase de infracciones la previsibilidad es el eje de la unión entre la acción y el efecto.

Las reglas que proporciona la teoría de la imputación objetiva se encuentran, en la actualidad, reconocidas como las válidas para solucionar los problemas de la causalidad. La imputación objetiva consta de dos elementos: "la existencia de relación de causalidad natural entre acción y resultado, y que el resultado sea expresión del riesgo creado y el fin de protección de la norma, de suerte que es el objetivamente imputable un resultado que está dentro del ámbito de protección de la norma penal que el autor ha vulnerado mediante una acción creadora de riesgo o peligro jurídicamente desaprobado" (STSS 15-11991,29-1-1993 y 1-2-2002).

Ahora bien junto a esto tenemos que tener en cuenta que es preciso referirse a otros conceptos relacionados con esta teoría y que conectan con la imprudencia en el ámbito sanitario. Sobre la base de la constatación de un peligro jurídicamente desaprobado, éste desaparece cuando se trata de riesgos permitidos (eficacia del consentimiento informado), que excluye la tipicidad de la conducta, y de casos de disminución del riesgo, es decir "en los que el autor obra causalmente respecto de un resultado realmente ocurrido, pero evitando a la vez la producción de un resultado más perjudicial" (STS19-10-2000).

Igualmente debe ponderarse junto con la causalidad, el principio de confianza "conforme al cual no se imputarán objetivamente los resultados producidos por quien obra en la confianza de que otros se mantendrán dentro de los límites del riesgo permitido" (STS 19-10-2000). Este principio tiene que ver con el trabajo en grupo, y se traduce en que un comportamiento conforme al cuidado exigido, autoriza a suponer que otros profesionales se comportarán de acuerdo con las obligaciones de cuidado que les incumplen". En efecto, la división del trabajo genera una confianza en el actuar diligente de los demás pro- 
fesionales de manera que a cada uno de los miembros del equipo no se les puede responsabilizar de los fallos de otro, salvo que la confianza en su actuación sea estimada infundada en atención a la entidad del error, o la ausencia de cualificación o fiabilidad del directamente responsable" (SAP Barcelona 12-52000). Así las cosas, que la división del trabajo sea horizontal o vertical no es tan trascendente y sí la función encomendada al profesional, abstracción hecha de su posición jerárquica en la cadena.

Por último debemos referirnos a la llamada prohibición de regreso, esto es, aquellas condiciones previas a las realmente causales, extrañas a quien se constituye en garante de la evitación del resultado (diagnóstico erróneo por otro facultativo u ocultación deliberada de antecedentes por el paciente). Evidentemente esta cláusula liberatoria de responsabilidad no afecta a aquellas omisiones en la elaboración del diagnóstico que no se realicen conforme a la lex artis. El respeto al principio de culpabilidad, por ende, impone esta exigencia y casa con la afirmación según la cual es imprescindible en un Estado de Derecho conocer la acción u omisión causalmente relevante para la producción del resultado y a quien se le atribuye, de manera que la imputación objetiva y las pruebas periciales valoradas con el resto de las practicadas forman con la configuración de la norma de cuidado en abstracto,(creándose así el riesgo no permitido o aumentando el consentido)los tres pilares sobre los que pivota, básicamente la imprudencia profesional en el concreto ámbito de la medicina.

En relación con lo anterior, también adquiere importancia en la actividad médica la concurrencia de cursos causales complejos, sobre todo cuando contribuyen a un resultado típico la conducta del acusado y además otra u otras causas atribuibles a otras personas distintas o a un suceso fortuito. La jurisprudencia establece como norma básica que no son imputables al médico que actúa las omisiones o errores de sus predecesores en la cadena de exploración y diagnóstico, salvo que sean tan crasos y notorios que su imperceptibilidad entronque con la infracción del deber de cuidado que tenía que observar.

\section{LA RESPONSABILIDAD DEL CENTRO HOSPITALARIO DE CARÁCTER PÚBLICO}

Como exponíamos al principio de esta ponencia en la actualidad se produce una desbordante presentación de reclamaciones de responsabilidad patrimo- nial en el ámbito sanitario público y que de no poner freno se corre el riesgo de llegar a un Estado providencialista, convertido en una aseguradora universal, que tuviera que atender cualquier reclamación que tenga por origen la actividad de la sanidad. La circunstancia de que la asistencia sanitaria no consiga restablecer la salud del paciente, no puede entenderse en todos los supuestos como una circunstancia que deba dar lugar a responsabilidad y ello a pesar de que pueda establecerse la oportuna relación de causalidad entre la asistencia prestada y el resultado de la falta de salud. Una cosa es la relación de causalidad y otra muy distinta es por el simple hecho de que se pueda establecer esa relación sea factible imputar el resultado a la prestación asistencial y no a la previa patología del paciente.

La jurisprudencia es clara en reconocer cuales son los requisitos que se precisan para que estemos ante un supuesto de responsabilidad del centro hospitalario. La STS de la Sala Tercera de fecha 10 de febrero de 1998 establece cuales son los requisitos necesarios para la existencia de responsabilidad patrimonial:

\section{a) Lesión patrimonial equivalente a daño} o perjuicio.

b) La lesión se define como un daño ilegítimo.

c) Vinculo entre la lesión y el agente que la produce, es decir entre el acto dañoso y la Administración.

d) La lesión ha de ser real y efectiva, nunca potencial o futura.

Ahora bien no puede haber responsabilidad del centro hospitalario público en todos los supuestos, sino que hay que delimitar los supuestos retributivos de verdadera responsabilidad patrimonial de la administración sanitaria. La correcta delimitación consiste añadir un plus a la exigencia de la relación de causalidad, que consiste en que la prestación sanitaria se haya producido con infracción de criterio de la lex artis de modo que la simple existencia de relación de causalidad no determina por sí la existencia de responsabilidad siendo exigible que la asistencia prestada, aún siendo formalmente correcta, haya infringido ese criterio de normalidad.

Como estamos ante una responsabilidad que tiene, por su propia naturaleza un carácter marcadamente objetivo, la aplicación de ese plus que permita reducir los supuestos en que haya lugar a la responsabilidad patrimonial de la administración sólo a los supuestos de verdadera necesidad, hace 
necesario atender no a criterios de ilicitud ó de culpa (propios de tras formas de responsabilidad) sino que debe atenderse a un criterio distinto como debe ser el de la corrección de la asistencia sanitaria prestada sobre la base de ese criterio de normalidad que representa la lex artis. De no obrar de este modo se produciría una objetivización excesiva de la responsabilidad del centro sanitario. Estos criterios de objetivización absoluta eran los seguidos por nuestra jurisprudencia hasta época relativamente reciente, pero actualmente la jurisprudencia mas moderna opta por el criterio de la lex artis como delimitador de la responsabilidad.

La sentencia del TS, sala tercera, de fecha de 2212-2001 entiende que en materia de responsabilidad patrimonial "el elemento de la responsabilidad desaparece frente al elemento meramente objetivo del nexo causal entre la actuación el servicio público y el resultado lesivo ó dañoso producido, si bien, cuando se trata del servicio sanitario médico, el empleo de una técnica correcta es un dato de gran relevancia para decidir si hay ó no relación de causalidad, ya que cuando el acto médico ha sido acorde con el estado del saber, resulta extremadamente complejo deducir si, a pesar de ello, causo el daño mas bien obedece a la propia enfermedad del paciente o a otras dolencias del mismo". Dicha sentencia une el concepto de infracción de lex artis con el relativo a la antijuridicidad de daño y considera que si la intervención estaba indicada y se ha realizado con arreglo al estado del saber del momento de que se trate, e resultado dañoso que pueda producirse no es antijurídico y, por lo tanto el paciente tiene la obligación de soportarlo.

En esta línea el art.141 de la Ley 30/92 tras la exigencia de que el daño debe ser antijurídico establece que " no serán indemnizables los daños que se deriven de hechos o circunstancias que no se hubieran podido prever ó evitar según el estado de los conocimientos de la ciencia ó de la técnica existentes al momento de producción de aquellos, todo ello son perjuicio de las prestaciones asistenciales ó económicas que las leyes puedan establecer para estos casos" .La Administración, si considera que en un caso concreto no hay responsabilidad por aplicación de la del art.141.1 de la Ley 30/92 deberá acreditar que no le fue posible a la Administración sanitaria evitar la producción del daño y que la actuación de la administración fue acorde a la lex artis del momento de prestación de la prestación sanitaria.

Sin embargo una sentencia de la misma Sala de fecha 7 de junio de 2001 relaciona la lex artis con la inadecuación de la prestación, dice la sentencia que "el titulo de imputación de la responsabilidad patrimonial por daños o perjuicios generados por la actividad administrativa puede consistir en el carácter inadecuado de la prestación médica llevada a cabo. Esta inadecuación pude producirse por incumplimiento la la lex artis ad hoc ó por defecto, insuficiencia ó falta de coordinación del servicio".

Por último respecto a la consideración del daño, este para que sea indemnizable tiene que ser antijurídico, es decir que el paciente no tiene la obligación de soportarlo. (SS de la sala de lo Contencioso de Audiencia Nacional, R 356/2000, R 516/2001, R 180/2000).

\section{EL NUEVO DELITO DE OMISIÓN}

Dentro de la terminología genérica de los delitos de omisión, podemos distinguir dos categorías. La primera es la de los delitos de omisión pura o propia, y, la segunda la de los de comisión por omisión u omisión impropia. La primera implica la vulneración de una norma preceptiva, mientras que la segunda viene referida a la producción de un resultado por parte de quien está obligado a realizar una actuación para evitar tal resultado. En este último supuesto entra en juego la postura del garante, que viene configurada con la obligación legal de actuar. Mientras que la omisión propia es el no actuar por cualquiera, indistintamente de que venga o no obligado a ello hay un deber genérico-, en la omisión impropia o comisión por omisión, sólo responde quien está obligado -hay un deber específico-.

En el Código Penal de 1995, se crea una figura delictiva de omisión nueva, que castiga, en su artículo 196 al «profesional que, estando obligado a ello, denegare asistencia sanitaria o abandonare los servicios sanitarios, cuando de la denegación o abandono se derive riesgo grave para la salud de las personas». Esta figura, si bien por su naturaleza y ubicación parece corresponderse con la de una omisión propia, no obstante, al requerir que el omitente de la asistencia esté obligado a ella, parece acercarla a los delitos de omisión impropia. Sin embargo, la realidad es que esta figura delictiva, se encuentra a mitad de camino entre ambas omisiones, pudiendo constituir un «tertium genus» con sus peculiaridades propias, en lo que algún autor ha denominado «omisiones propias de garante». Se castiga el no actuar debiendo hacerlo, pero sin causar un resultado lesivo para las personas, porque si de la omisión se desprendiera la causación de unas lesiones irreversibles 
o, incluso, la muerte, el omitente, al estar obligado a actuar se convertiría en autor por omisión de dichas lesiones o de la muerte. Así como en el delito genérico de omisión del deber de socorro se castiga el comportamiento insolidario, siendo el bien jurídico protegido la solidaridad humana, en este tipo específico, el bien jurídico protegido es, en primer lugar, el deber profesional y, en segundo, la salud de las personas.

El sujeto activo de este delito es, obviamente, el profesional de la sanidad, pudiendo referirse tal denominación a los médicos, enfermeros, ATS, auxiliares así como celadores y conductores de ambulancias. Pero para que concurra este delito no basta con el requisito subjetivo mencionado, sino que es preciso que dicho profesional esté obligado a ello. No cometerán este delito, por tanto los profesionales sanitarios cuando se encuentren libres de servicio, pudiendo entonces incurrir en un delito genérico de omisión del deber de socorro. Esta obligación, elemento normativo del tipo, será la legal o contractual de actuar, no bastando con la mera obligación moral, con la que, de algún modo, compele el Código deontológico. Es decir, está obligado a actuar el médico que está de servicio, que se encuentra de guardia y al que acude el enfermo confiando en recibir asistencia. Se ha dicho que está obligación del médico de servicio, es una obligación genérica hacía todos los pacientes, pero ello no es óbice para que, en cada caso particular, se convierta en una obligación concreta hacia el enfermo que acude a solicitar el auxilio médico.

En el caso del ejercicio del derecho de huelga llevado a cabo por personal sanitario, hay que tener en cuenta que esta obligación de actuar, implica el límite al ejercicio del derecho, existiendo responsabilidad criminal, exigible, en principio, por este precepto, cuando quien está obligado -servicios mínimos- no actúa.

La conducta omisiva a realizar, puede revestir dos modalidades. Se puede materializar en la denegación de la asistencia sanitaria o en el abandono de los servicios sanitarios. La primera de ellas, consiste en que, estando presente el sanitario, no accede, por la razón que sea, a atender a un enfermo que acude en petición de auxilio, mientras que la segunda de ellas, se refiere al supuesto de ausencia del sanitario de su puesto de trabajo, lo que, lógicamente acarrea la desatención o desasistencia de cualquier enfermo que se pueda presentar. Hay que tener en cuenta que la desatención no sólo implica que el médico de guardia deje de asistir a una persona que le necesita, sino que también abarca al supuesto en que, impedido el médico de prestar la asistencia requerida, omita el demandar el auxilio de otros organismos médicos, así como aquellos supuestos en que la asistencia sea tardía, habiendo sido equiparado por el Tribunal Supremo la tardía intervención con la abstención.

Aún es necesario otro requisito para que la conducta sea penalmente reprochable y es la necesidad de que, de la denegación o abandono, se derive riesgo grave para la salud de las personas. Este requisito, en cierto modo perturbador, ha sido introducido en el tipo con la finalidad de que únicamente tenga trascendencia penal la conducta del sanitario que desoye los requerimientos de quien realmente le necesita. Quedan así fuera del tipo aquellas desatenciones ocasionadas frente a requerimientos innecesarios. El sanitario que requerido por una persona que no se encuentra en una situación de peligro, le deniega la asistencia, podrá incurrir en responsabilidad administrativa, pero la escasa trascendencia real de tal omisión hace desaconsejable que se aplique el Código Penal. Decíamos que es un requisito perturbador, sin embargo, porque la literalidad del precepto obliga a que tal riesgo grave se produzca a consecuencia de la denegación o abandono. Riesgo grave existirá siempre que una persona presente peligro de sufrir lesiones irreversibles o la muerte. ¿Qué sucederá cuando la persona desatendi$\mathrm{da}$, con graves dolencias, hubiera muerto o sufrido lesiones irreversibles pese a la pronta atención? La medicina no es una ciencia exacta, siendo imposible predecir con total certeza. Se podrá decir que normalmente o, por regla general, o casi seguro, la persona hubiera muerto o quedado con unas secuelas, pero difícilmente se podrá asegurar con total rotundidad. Pese a ello, el resultado inevitable, haya o no asistencia, es un dato que, apriorísticamente no se puede predecir. El sanitario debe actuar conforme a su «lex artis», aplicando los medios adecuados tendentes a sanar o a mejorar el estado del enfermo. La sanación no es su obligación, sino la aplicación de los medios tendentes a ella. Por ello estimo que es indiferente para el tipo penal que la persona falleciera o quedara con secuelas a pesar de haber sido atendida. Lo importante es que la persona que se encuentre necesitada médicamente de la asistencia la reciba, o como ha dicho nuestro Tribunal Supremo «sin que sea óbice para esta condigna sanción que las lesiones que padecía y determinaron su fallecimiento fueran mortales de necesidad, pues en tanto perdura la vida se mantiene el deber de auxilio y la de allegar los medios aconsejados por la ciencia para intentar evi- 
tar la muerte». Además, en los supuestos en los que la muerte o las lesiones se produzcan como consecuencia de la denegación de auxilio, este resultado le será imputado al médico, respondiendo entonces no ya por la omisión de la atención sino por el resultado producido.

\section{ESPECIAL CONSIDERACIÓN AL CONSENTIMIENTO INFORMADO Y SU INCIDENCIA EN UNA POSIBLE RECLAMACIÓN POR RESPONSABILIDAD}

El consentimiento informado constituye una parte de la asistencia clínica prestada al paciente, luego es una acto clínico mas. En su acepción mas básica implica la obligación de informar de todos los riesgos y beneficios ligados al tratamiento o a la intervención propuesta para que el paciente decida de acuerdo con su criterio (Sanchez Caro). Desde el punto de vista legal la ley 41/2002 de 14 de Noviembre en su art.3 lo define como "la conformidad libre y voluntaria y consciente de un paciente, manifestada en el pleno uso de sus facultades después de recibir información adecuada, para que tenga lugar una actuación que afecta a su salud".

$\mathrm{Su}$ exigencia forma parte de la prestación sanitaria que realizan las Administraciones, lo que implica que esa exigencia, y dado el caso, omisión tiene trascendencia jurídica no solo en cuanto a la observancia de las normas reguladoras, sino también de índole patrimonial tal y como señala la jurisprudencia.

El instituto del consentimiento informado ha evolucionado desde su exigencia como regla general y su comprensión, hasta llegar al terreno de la responsabilidad en cualquiera de sus vertientes. Este instituto muestra, en el ámbito de la relación jurídico -sanitaria, el terreno que gana el usuario de un servicio público en forma de derecho y su patrimonialización ya que se reconoce su exigibilidad y a la par su derecho a ser resarcido.

En este sentido, si que parece que en buena medida el instituto del consentimiento informado gana en su entidad jurídica si va de la mano de la responsabilidad, como un elemento mas integrante de un iter causante de un daño jurídico, precedido por tanto de la quiebra de la lex artis . La consideración jurídica y mas en concreto judicial del instituto del consentimiento depende de que se ocasione un daño resarcible. De esta forma, hablar de responsabilidad patrimonial a propósito del consentimiento informado nos lleva a la idea de un funcionamiento anormal del servicio público sanitario, ahora bien se requiere que se produzca ese daño efectivo, individualizado y económicamente evaluable y que entre el funcionamiento del servicio y el daño medie la lógica relación de causalidad. Las quiebra de las reglas que regulan el consentimiento informado ¿dan derecho al resarcimiento?; y en caso positivo ¿en qué debe consistir ese resarcimiento?

Para responder a estas cuestiones debe compaginarse la infracción de esas normas con la consecuencia de la actuación médica pues no es lo mismo que concurra esa quiebra con una actuación médica correcta en lo material, que con una actuación médica cuyo resultado implique una quiebra de la lex artis referida a la pericia médica en sentido estricto. $\mathrm{Y}$ así podrían darse los supuestos siguientes:

\section{A-Casos de inexistencia de lesión física}

Nos referimos a los supuestos en los que en mayor o menor grado se ha infringido la normativa sobre consentimiento informado pero, sin embargo la intervención médica ha sido satisfactoria en sentido estricto para el paciente. En estos supuestos no procede resarcimiento alguno pues no existe daño, ahora bien a la vista de la consideración jurisprudencial del consentimiento, en el sentido de que se basa en la autonomía de la persona- paciente, en el respeto a la dignidad, al haberse lesionado ese valor moral debería generar responsabilidad.

B-Actuación conforme a la lex artis, pero

concurriendo un riesgo típico previsible

Estamos ante intervenciones técnicas que en lo técnicas son conformes a la lex artis pero, no obstante el paciente ha sufrido una secuela o se ha producido un resultado de los tenidos como riego inherente o previsible. La ausencia de consentimiento informado supondría que se traslada la responsabilidad por el resultado dañoso del paciente, al médico, lo que motivaría que la lesión causada por un riesgo inherente a la intervención deviene en antijurídica, luego por no haber mediado esa información el paciente no tiene el deber jurídico de soportarlo. Habría que ver en cada caso en que ha consistido la infracción del consentimiento, si se trata de un supuesto de absoluta carencia o si la omisión lo ha sido de los riesgos previsibles o la información sobre posibles alternativas.

C-Actuación médica conforme

la lex artis, pero concurriendo un riesgo

atípico, imprevisible o fuerza mayor

Como en los anteriores supuestos la intervención médica ha sido conforme a las reglas de la lex artis, pero de resultas de esa intervención técnicamente 
correcta se deduce un resultado dañoso por causa de un riesgo atípico, imprevisible o fuerza mayor. La fuerza mayor rompe el nexo de causalidad entre la prestación del servicio, luego no es imputable a la Administración.

\section{D-Infracción del régimen del consentimiento informado y quiebra de la lex artis médica}

Se trataría de los casos en los que concurren los dos tipos de quiebra de la lex artis, la estrictamente médica, más la ligada a la quiebra del régimen del consentimiento informado. En estos casos la infracción de la lex artis asociada al régimen del consentimiento informado sería a más, es decir, a los efectos de su indemnizabilidad lo propio sería estar a la lesión física de forma que el dato de la lesión de la autonomía de la persona y su dignidad actuaría como elemento de la cuantía de la indemnización.

\section{BIBLIOGRAFÍA}

1. Guerrero Zaplana, José: "Las peculiaridades de la responsabilidad patrimonial de la Administración Sanitaria, el criterio de las lex artis". La Responsabilidad patrimonial de la Administración sanitaria. Cuadernos de Derecho Judicial 2002.

2. Zamarriego Crespo, José: "Los médicos y el consentimiento informado”. En Deontología, función social y responsabilidad de las profesiones sanitarias. Universidad Complutense de Madrid y Banco de Santander Central Hispano, Madrid 1999.

3. Sanchez Caro, Jesús: "Consentimiento informado en psiquiatría. Revisión y diagrama para su aplicación en España”. Comu-nicación al VI Congreso de Derecho Sanitario. Asociación Españo-la de Derecho sanitario y Fundación MAPFRE. Madrid 2000.

4. Cortés Bechiareli Emilio: "El ejercicio de las profesiones Sanitarias y delitos imprudentes" La imprudencia. Cuadernos de Derecho Judicial .XVI .2005.

5. Rives Seva, José María: “Consideraciones generales acerca de la responsabilidad civil médica y sanitaria” Diario La Ley n6011. 5 de Mayo de 2004. 